Manuscript type: Article

\title{
Using Landsat 8 images along with Google Earth Engine for investigation the location of the crashed aircrafts
}

\author{
Azad Rasul 1, * \\ 1 Department of Geography, Soran University, Kawa Street, Soran 44008, Erbil, Iraq \\ * Correspondence: azad.rasul@ soran.edu.iq or aor4@alumni.le.ac.uk; Tel.: +964-(0)750-735-8574
}

\begin{abstract}
Remote sensing data and techniques utilized for various purposes including natural disasters such as earthquake as well as flood. The research aims to consume liberates Landsat 8 images for investigating crashed airplanes such as MH370. Overall approximately 300 Landsat images with less than $10 \%$ clouds utilized in addition processed through Google Engine Platform. Due to the materials as well as the color of airplane body different from the area which is a plane crashed there, moreover, it should be the characteristics of the plane shapefile different in terms of albedo, temperature as well as vegetation index value. The research observed Landsat 8 data as well as methods utilized in this research, especially, NDVI, albedo in addition to band 4, capable to distinguish between the plane and its surrounding green area. Therefore, our result confirms during the research period, there was no plane on the location as well as MH370 not crashed in this site.
\end{abstract}

Keywords: crashed aircraft; NDVI; albedo; MH370; remote sensing; Landsat 8; disaster; Boeing 777; panchromatic band; thermal band

\section{Introduction}

Remote sensing as a valuable source applied successfully in several natural disaster events around the world ${ }^{1}$. Due to it is capable of assist to identify natural disaster's damages as well as furnish maps of the near actual time of the disaster ${ }^{2}$. For instance, it is data and techniques such as SAR, optical and thermal, LiDAR detection, applied for landslides, volcanic activity, earthquakes and faulting, flooding, wildfire ${ }^{3-7}$. There is a possibility to use it for disappeared aircraft more broadly.

A Malaysian Airlines Flight MH370 disappeared on the morning of $8^{\text {th }}$ of March 2014 with 227 passengers besides 12 crew members ${ }^{8,9}$. The type of aircraft is Boing 777 which is one of the world's largest aircraft. It has the capacity to travel a range of 9,695 to $17,372 \mathrm{~km}$. MH370 was on a routine flight from Kuala Lumpur to Beijing ${ }^{10}$. Rolls-Royce's (the engine manufacturing company), confirmed that they had received a health report for five hours. It means that the aircraft had remain flying for four hours ${ }^{11}$.

Besides a long, wide as well as expensive search for MH370, the story of missing it remain a mystery. According to Malaysian Safety Investigation Team for MH370, by now (2018), 27 suspected and confirmed fragments were found ${ }^{9}$. Discovered debris up to now in South Africa, Reunion, Mozambique as well as Rodrigues Island presumably derived from the wide search 
area between latitude 28 and 35 South $^{8}$. To determined location of MH370, drift studies focused on the spatial distribution of the derbies or on the aerial search ${ }^{9,12}$. During September of 2018, after four years and half of missing MH370, British photographer Ian Wilson confirmed what a YouTube video claimed in 2014 which is a plane appeared on Google Earth inside a jungle in Cambodia believing it is MH370. Before going to the field, remote sensing has capabilities to obtain more information regarding these locations and allegations.

Generally, remote sensing has high ability to find change detection as well as investigate disasters even in remote and not easily reachable locations such as dense jungles through compare images of before and after events. One of its advantages is it is capable of consuming several techniques, band compassion and indices and it is not only relying on visible images. However, several factors have a role in remote sensing capacity to investigation objects such as the resolution of the images as well as cloud situation.

In remote sensing, quickly and accurately airport and aircraft detection are substantial for several civilian as well as military purposes ${ }^{13}$. As a reason of simple sky background, detection of flying airplanes is easy in comparison to airplanes on the ground due to the intervention of the surrounding area and color features. Usually, the first step of airplane detection methods are location candidate regions and the second is classifying objects ${ }^{13}$. Aircraft detection consumes templates matching which is an approach to finding diminutive objects in digital image processes ${ }^{14}$. In previous years, methods of an airport as well as airplane detection developed considerably ${ }^{15-19}$. However, these researches usually utilized Google Earth or visible bands of high-resolution satellite images.

In 2013, Landsat 8 was launched with two sensors, the Operational Land Imager (OLI) and the Thermal Infrared Sensor (TIRS). To monitor terrestrial change detection, Landsat data are crucial $^{20}$. Landsat 8 data utilized for different research fields, for instance, urban expansion, a variation of land surface temperature, global land change, land cover classification, mapping of ice flow ${ }^{21-24}$. To the best of our knowledge, Landsat 8 , not used for study missing aircraft before thus this study selected it for this purpose. While Landsat is a medium resolution optical satellite, it has several advantages, for instance, Landsat data freely available for a long period and it has multi-spectral bands.

Generally, remote sensing is engaging effectively in the search for the MH370 ${ }^{10}$. For instance, the final route of MH370 determined above the Southern Indian Ocean by the International Maritime Satellite Organization (Inmarsat) based on automatic communication between one of its satellites and the airplane ${ }^{9,10}$. Moreover, during the research operation for MH370 on the sea surface, radar as well as infrared sensors equipment utilized by the Lockheed Martin P-3 Orion ${ }^{10}$. However, there is other remote sensing data and techniques can play a greater role in this disaster.

While remote sensing images and techniques utilized for different natural as well as human disasters, in literature we have not observed scientific research used Landsat images for investigating disappeared or crashed airplane. The objective of this study is to prove the ability of Landsat 8 as freely available satellite image to discover a missing plane landed inside the 
dense jungle. Moreover, it attempts to consume remote sensing to contribute in search of MH370 through the experiment is there airplane on the claimed crash site of the plane or it is just routine flying of the plane during satellite image acquisition.

\section{Materials and methods}

\subsection{Study sites}

The research was conducted in three locations which situated in different countries. For each case the shapefile of the plane in addition to one site selected as a reference to compare with the location of the aircraft.

\subsubsection{The claimed crash site of MH370 in Cambodia:}

The study site in Cambodian Jungle located in $12^{\circ} 05^{\prime} 20^{\prime \prime} \mathrm{N}$ latitude and $104^{\circ} 09^{\prime} 06^{\prime \prime} \mathrm{E}$ longitude inside Pursat province. The reference site is forest area which is located in the east direction and it is close to the mentioned location of the plane (Figure 1). The area is part of Phnom Aural Wildlife Sanctuaries which is established in 1993 and it is located in the South of Chrak Loieng Waterfall. The area is dominated by evergreen forest. In high elevation evergreen forest, in the area, dominate trees type are 'conifer-oak' and/or 'oak-laural.' Fagaceae, Lauraceae, Myrtaceae, and Podocapaceae ${ }^{25}$. Regarding the climate, the average temperature of the province is $32.5^{\circ} \mathrm{C}$ and the annual rainfall is $1,487.42 \mathrm{~mm} /$ year $^{26}$.

\subsubsection{Heathrow Airplane site in the UK:}

Heathrow Airport located in $23 \mathrm{~km}$ to the west of center in the district of Longford, Hounslow, in Greater London. It is latitude is $51^{\circ} 28^{\prime} 39^{\prime \prime} \mathrm{N}$ and it is longitude is $000^{\circ} 27^{\prime} 41^{\prime \prime} \mathrm{W}$ with the elevation of $25 \mathrm{~m}$ above sea level. Regarding the climate, annual rainfall of the airport is $601.7 \mathrm{~mm}$ and the annual maximum temperature is $15.2^{\circ} \mathrm{C}$ and the annual minimum temperature is $7.5^{\circ} \mathrm{C}$. Average annual sunshine hours is $1632.6^{27}$. For the study site, only one aircraft stand selected as a shapefile of the plane and the reference site selected outside the airport in the green area located in the west of the airport (Figure 1).

\subsubsection{Airplane Home site in the US:}

A Boeing 727-200 converted into a residence located in 15270 SW Holly Hill Rd, Hillsboro, Oregon, USA. It is latitude is $45^{\circ} 24^{\prime} 29.1^{\prime \prime} \mathrm{N}$ and it is longitude is $123^{\circ} 00^{\prime} 28^{\prime \prime} \mathrm{W}$ (Figure 1). The elevation of Hillsboro is $59 \mathrm{~m}$ above sea level. The area is rolling hill and the landscape covered by orchards. The airplane is surrounded by high pines. Regarding the climate, average annual rainfall in Hillsboro is $954 \mathrm{~mm}$ and the average temperatures range between 5.61 ${ }^{\circ} \mathrm{C}$ and $17.2^{\circ} \mathrm{C}^{28}$. The reference site is selected inside the tree area in the North West of the Airplane Home and it is approximately $1 \mathrm{~km}$ far from it. The location of the reference site is $45^{\circ} 24^{\prime} 49^{\prime \prime} \mathrm{N}$ latitude and $123^{\circ} 01^{\prime} 13.4^{\prime \prime} \mathrm{W}$ longitude. 

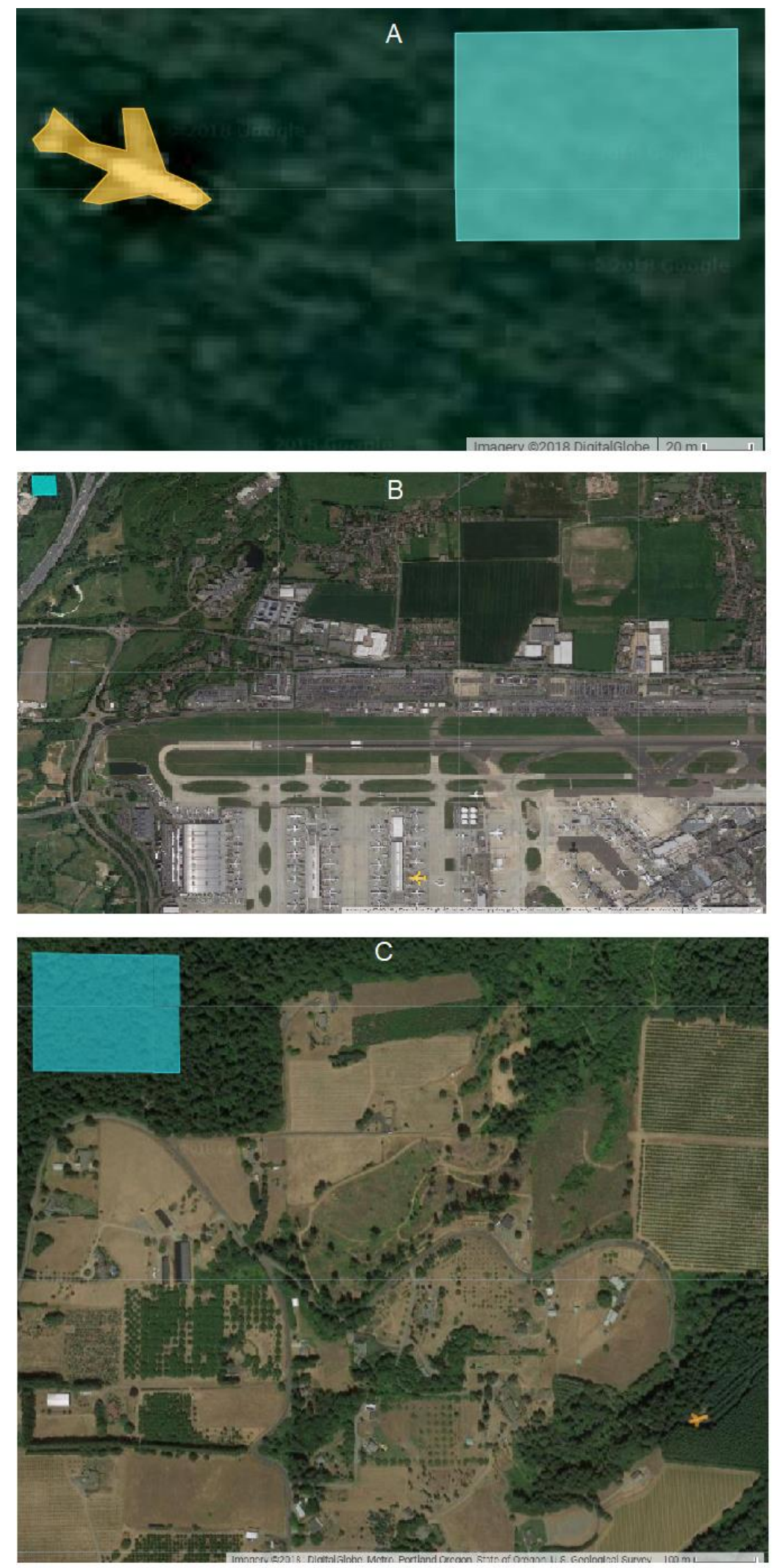

Figure 1: Study sites. A: Cambodian Jungle, B: Heathrow Airport in the UK, C: Airplane Home in the US. 


\subsection{Data}

Overall approximately 300 of freely available Landsat 8 data from 2013 to 2018 for the study sites utilized in this research (Appendix 1).

\subsection{Methodology}

In order to achieve objects of this research as well as evaluate the capacity of the free satellite image of Landsat 8, overall approximately 300 Landsat images with less than 10\% clouds used and processed through Google Engine Platform ${ }^{29}$. As an experiment case of using albedo, NDVI, spectral, panchromatic as well as thermal bands method for the difference between plane area and sample background, samples of Heathrow in the UK and Airplane Home in the US selected. Then as validation, these methods applied with Cambodian Jungle case.

\subsubsection{Albedo}

The surface albedo is the fraction of reflected solar radiation by the surface to the received radiation ${ }^{30}$. In the investigation of missing airplane, the albedo of materials has a great role. Usually, civilian airplanes are made of aluminum and painted with white color. The albedo of white painted aluminum material is 0.80 while for instance, the albedo value of the coniferous forest is between 0.09 to 0.15 and the albedo of pennaceous forests is between 0.15 to $0.18^{31,32}$. Therefore, a plane should have higher albedo, especially if it is crashed in a vegetated area like the claimed crash site of MH370 in the Cambodian jungle. Due to cloudy pixels usually have a high albedo, only images with less than $1 \%$ of cloud used. As a result of having a cloud above the study site, Landsat 8 images of 2014 excluded while 62 transparent satellite images from 2015 to 2017 used. According to ${ }^{33}$, Eq. 1 used for retrieval the land surface albedo.

$$
\begin{gathered}
\text { Albedo }=((0.356 * \text { blue })+(0.130 * \text { red })+(0.373 * \text { nir })+(0.085 * \text { swir } 1)+(0.072 \\
\quad * \text { swir } 2)-0.018) / 1.016
\end{gathered}
$$

where blue is B2, red is reflectance B4, nir is B5, swirl is B6, swir2 is B7. For mentioned bands TOA reflectance used.

\subsubsection{NDVI}

NDVI is the simple as well as widely used vegetation index. It is a ratio-based index using two bands (red and near infrared) to recognize healthy flora and green biomass differences due to vegetation has a strong assimilation in the red band and a strong reflection of the solar radiation in the NIR band ${ }^{34}$. For NDVI comparison, less than $10 \%$ cloud images from 2013 to 2016 used. For NDVI comparison overall 88 satellite images used. NDVI is calculated as follows:

$$
N D V I=\frac{(\rho N I R-\rho R E D)}{(\rho N I R+\rho R E D)}
$$

where $N D V I$ is normalized difference vegetation index, $\rho N I R$ is the surface reflectance of band 5 and $\rho R E D$ is the surface reflectance of band 4 in Landsat 8. NDVI values range from -1.0 to +1.0. High NDVI values (about 0.6 to 0.9 ) related to dense vegetation such as temperate and tropical forests ${ }^{35}$. While NDVI value of inanimate elements such bare soil is quite low. 
Therefore, the NDVI value of vegetated background should be higher than the NDVI value of airplane shapefile.

\subsubsection{Spectral difference}

Spectral characterization of the Operational Land Imager (OLI) is disclosed in Appendix 1. In Landsat 8, Costal, Blue, Green and Red bands, aluminum has higher reflectance than vegetation (Appendix 2). For spectral comparison overall 22 satellite images with less than $10 \%$ cloud for 2014 used.

\subsubsection{Panchromatic difference}

The bandwidth of the panchromatic band Landsat 8 has covered the red, green and blue bands in the grayscale image ${ }^{37}$. Panchromatic band in Landsat OLI is band 8 and it has the highest spatial resolution $(15 \mathrm{~m})$. For panchromatic comparison overall 31 satellite images with less than $10 \%$ cloud for 2014 used. The value of the airplane in panchromatic band anticipates being higher than its value on the vegetated background.

\subsubsection{Thermal band difference}

Differences between thermal characteristics of objects are capable of being measured by means of thermal sensors. For thermal band comparison overall 96 Landsat 8 images with less than $10 \%$ cloud from 2014 to 2017 used. Bands 10 and 11 of Landsat 8 Thermal Infrared Sensor (TIRS) instrument are the thermal band, however, in this study, Band 10 used due to it is retrieval LST more accurately.

\section{Results}

As a result of using free Landsat 8 images from 2013 to 2018 besides using multi techniques, the research disappeared there is not a plane in the study site due to not any significant changes occurred in visible true and false color, thermal, panchromatic, NDVI and albedo values in the location.

\subsection{Albedo:}

In Heathrow case study, the average albedo of the plane area was $0.17 \pm 0.03$ while average albedo of the green reference was $0.013 \pm 0.02$ (Figure 2). It means albedo of the plane shapefile was 0.04 higher than the albedo of the reference. In a sample of Airplane Home, the average albedo of the plane shapefile was $0.13 \pm 0.09$ while average albedo of the reference was $0.09 \pm 0.02$ and it is albedo 0.036 less than albedo of the plane. Experiment case samples suggest that albedo is effective for differentiating between plane and green background reference.

In the Cambodian Jungle case, an average of claimed airplane shapefile was $0.117 \pm 0.016$ and average albedo of forest reference sample was $0.12 \pm 0.017$. It means no significant difference found between them in addition albedo of reference is 0.003 higher than albedo of the plane. While, logically if the plane is located in the location, it's albedo should be higher than albedo of the background forest. 


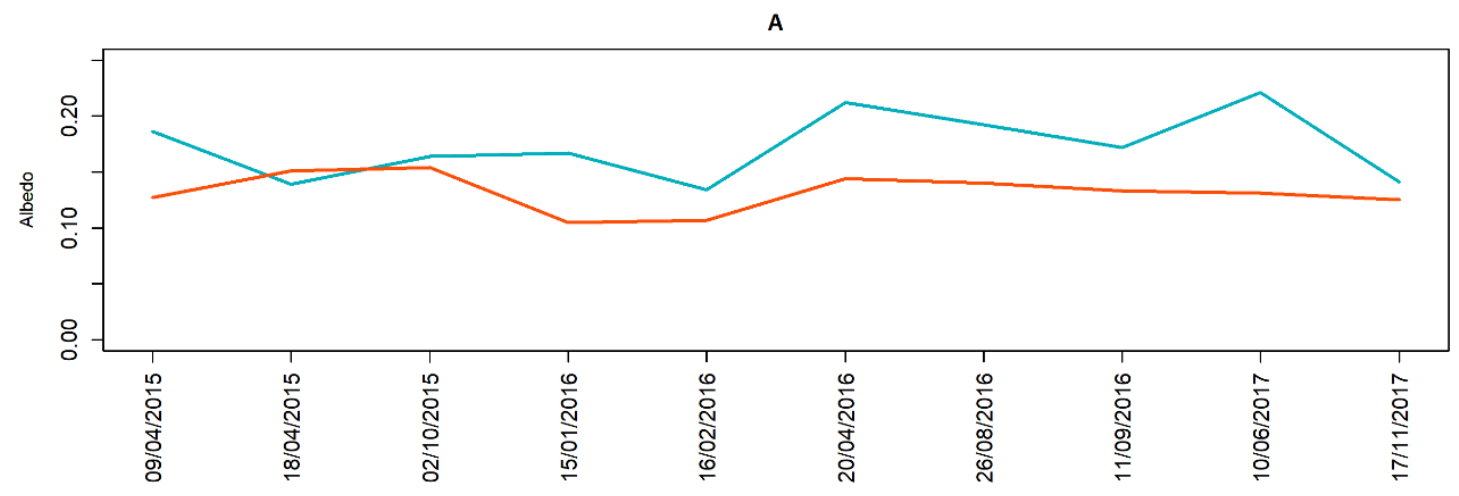

B

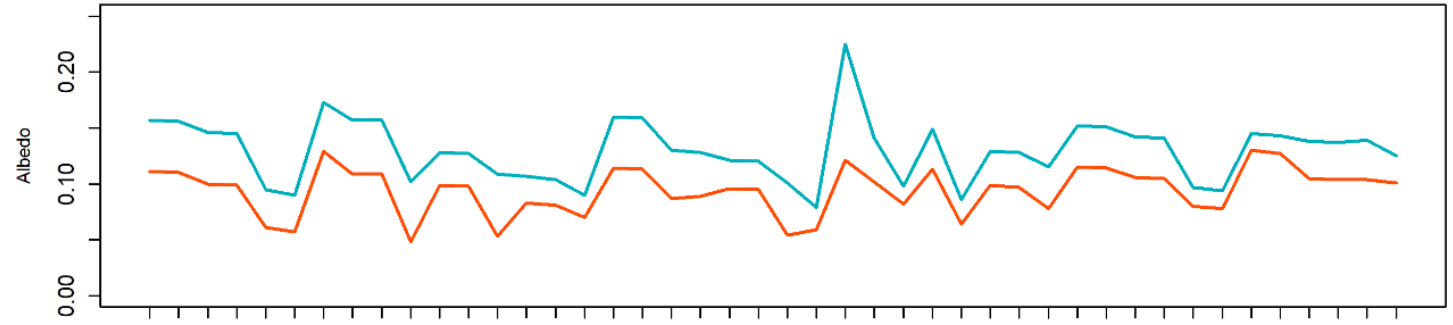

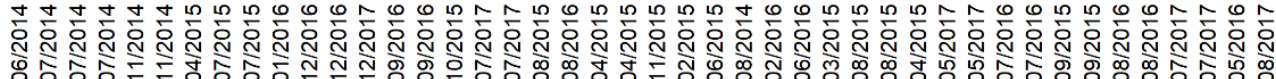

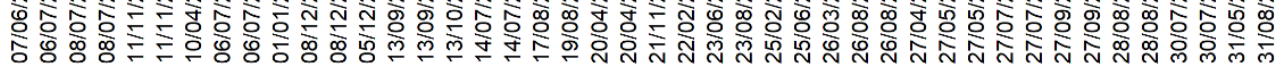

C

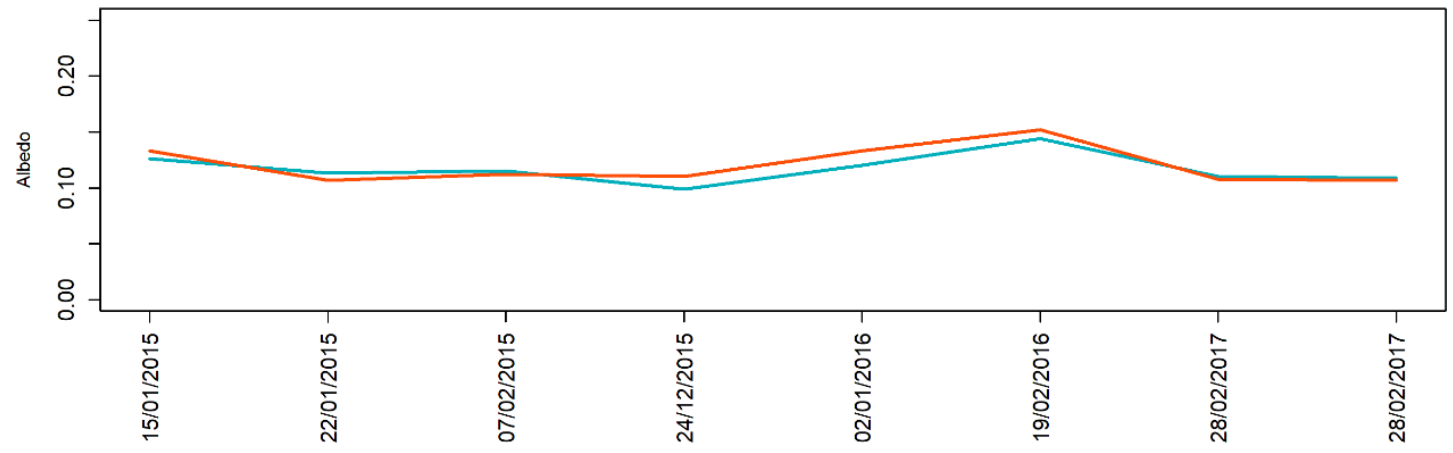

Figure 2: Albedo difference between the plane and reference site from Landsat 8. A: Heathrow Airplane, B: Airplane Home in the US, C: Cambodian Jungle. Blue is airplane shapefile and orange is a reference.

\subsection{NDVI:}

In Heathrow Airport case study, average NDVI of the plane site was $0.018 \pm 0.02$ while NDVI of green reference area was $0.68 \pm 0.14$ (Figure 3). It means NDVI of the plane site is 0.67 higher. In the Airplane Home case study, average NDVI of the plane was $0.77 \pm 0.09$ besides it is less than NDVI of the reference by 0.09 . Usually, NDVI of the reference higher, however, sometimes NDVI of the reference less than NDVI of the plane site. It means using average is facilitating while using only NDVI of one satellite image not valuable for differentiating between a plane and its reference background.

Regarding the Cambodian Jungle case study, there is not a significant difference between the claimed crash site of the airplane and the green reference. Average NDVI of the plane site was $0.885 \pm 0.03$ and NDVI of the reference was $0.887 \pm 0.03$. It suggests that during the study period there was no a plane in the location of the claimed of discovered MH370 in Cambodia. 


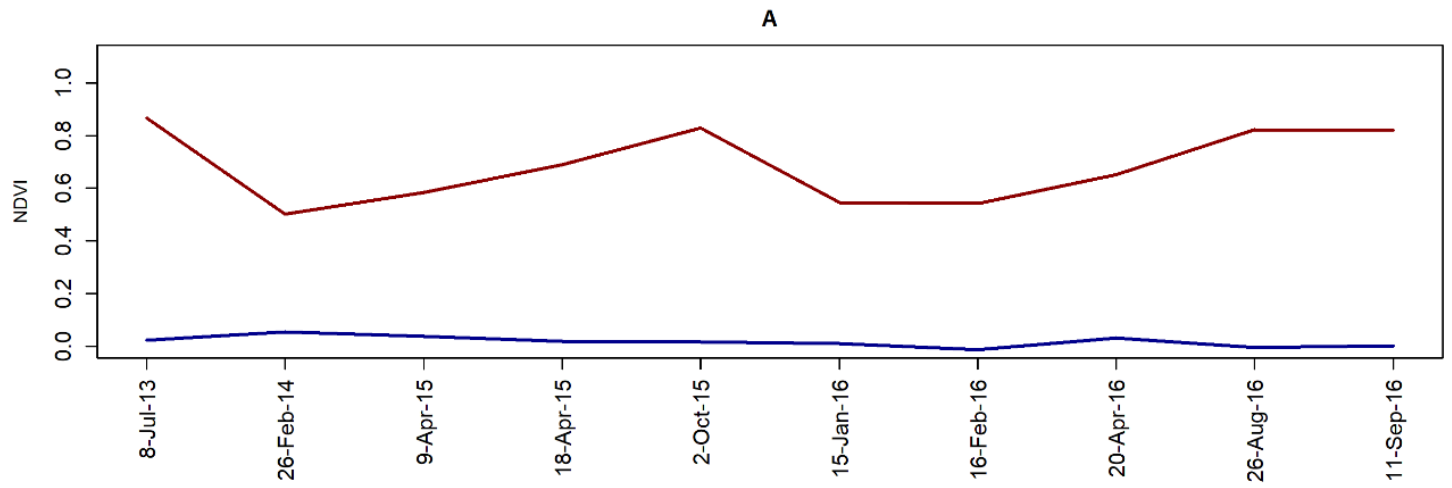

B

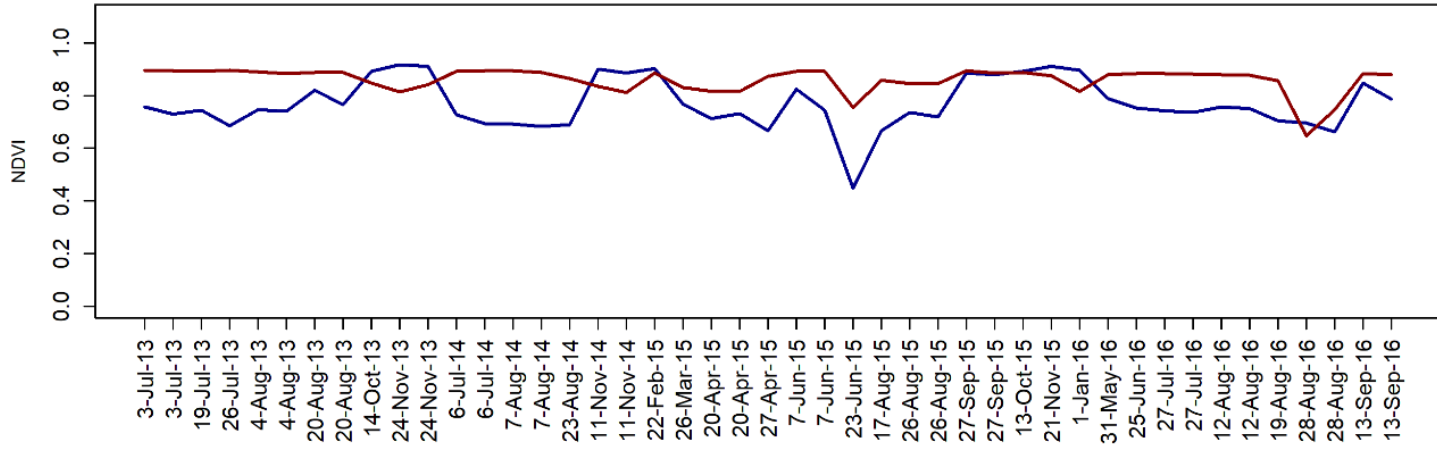

c

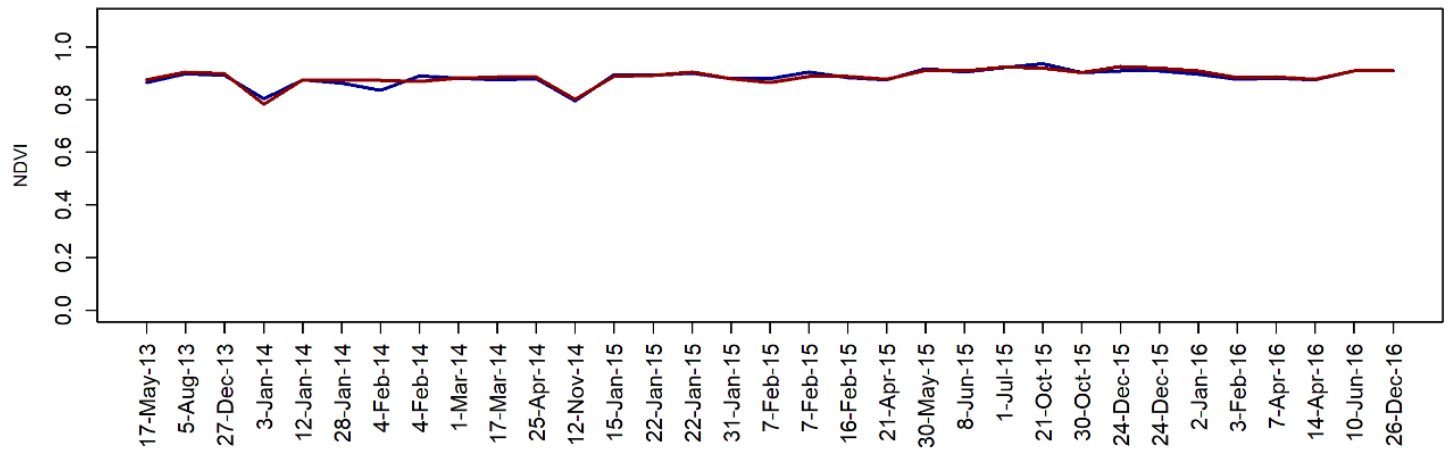

Figure 3: NDVI difference between the plane and reference sites from Landsat 8. A: Heathrow Airplane, B: Airplane Home in the US, C: Cambodian Jungle. Blue is airplane shapefile and red is a reference. 


\subsection{Spectral Difference:}

In Heathrow Airport case study, plane shapefile has higher reflectance than the reflectance of the reference site in bands 1, 2, 3, 4 and 8 (Figure 4). In bands 5, 6, 7 and 9 the values have fluctuated. The largest spectral difference observed in band 4 with $0.27 \pm 0.14$ and $0.09 \pm 0.02$ reflectance of the plane shapefile and reference, respectively. In case of Airplane Home, in bands 1 to 8, the reflectance of airplane site was higher than the reflectance of the reference site and in the band 5 , the spectral difference reaches highest when the reflectance was $0.27 \pm 0.06$ and $0.23 \pm 0.08$ for both the airplane and reference sites, respectively. It means the reflectance of the plane is 0.4 higher. The experiment case samples suggest that we are capable of consuming spectral differences from bands 1 to 5 of Landsat 8 to differentiate between an airplane and vegetated reference sites.

Whereas in the case of Cambodian Jungle, from band 1 to 9, there are only neglectable differences between airplane shapefile and reference. The result confirms that the pixels of both areas of claimed crashed MH370 and the reference dominated by tree and vegetation. For instance, the average reflectance of airplane shapefile in band 5 was $0.272 \pm 0.039$ and reflectance of reference was $0.27 \pm 0.037$. 

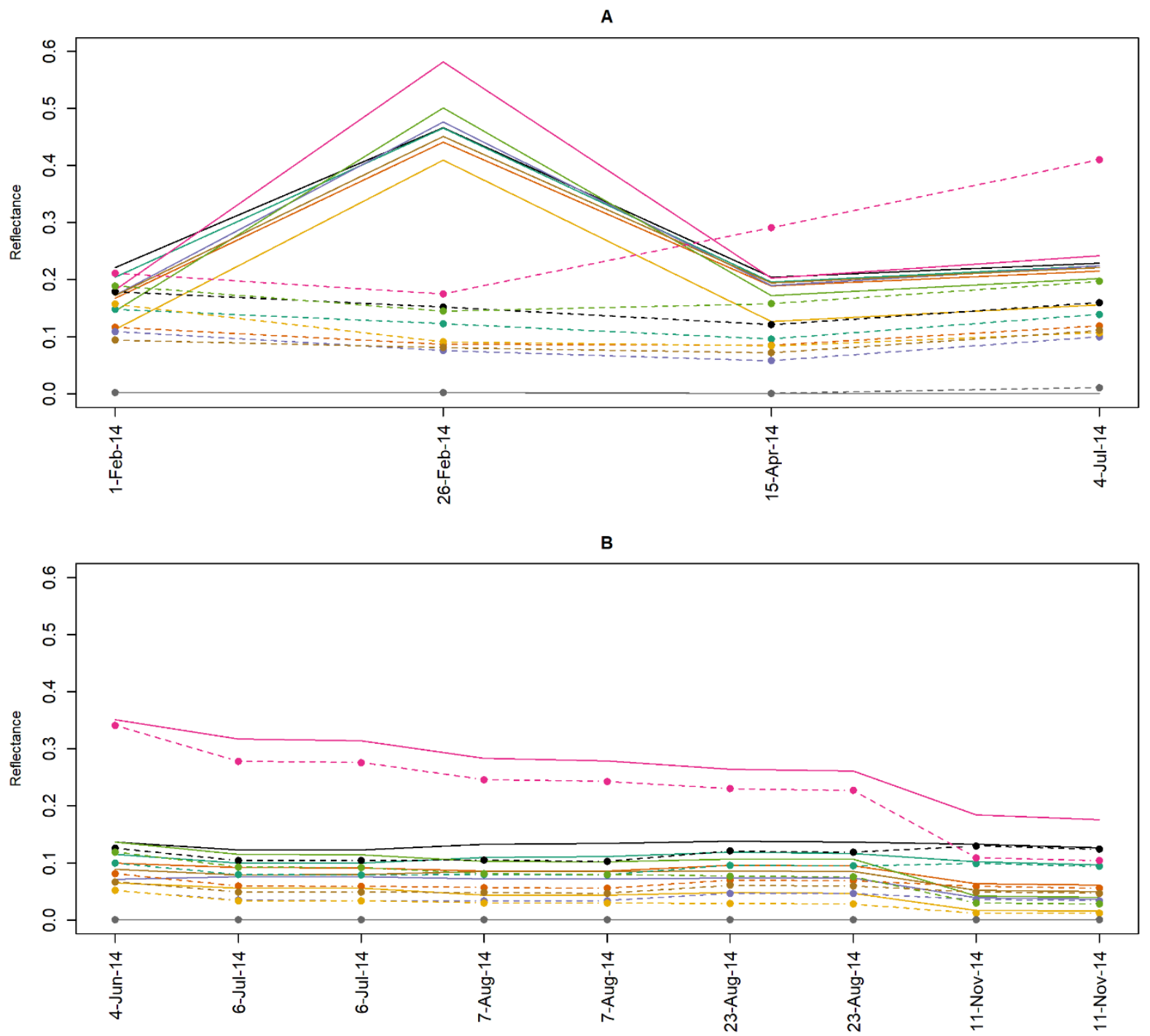

C

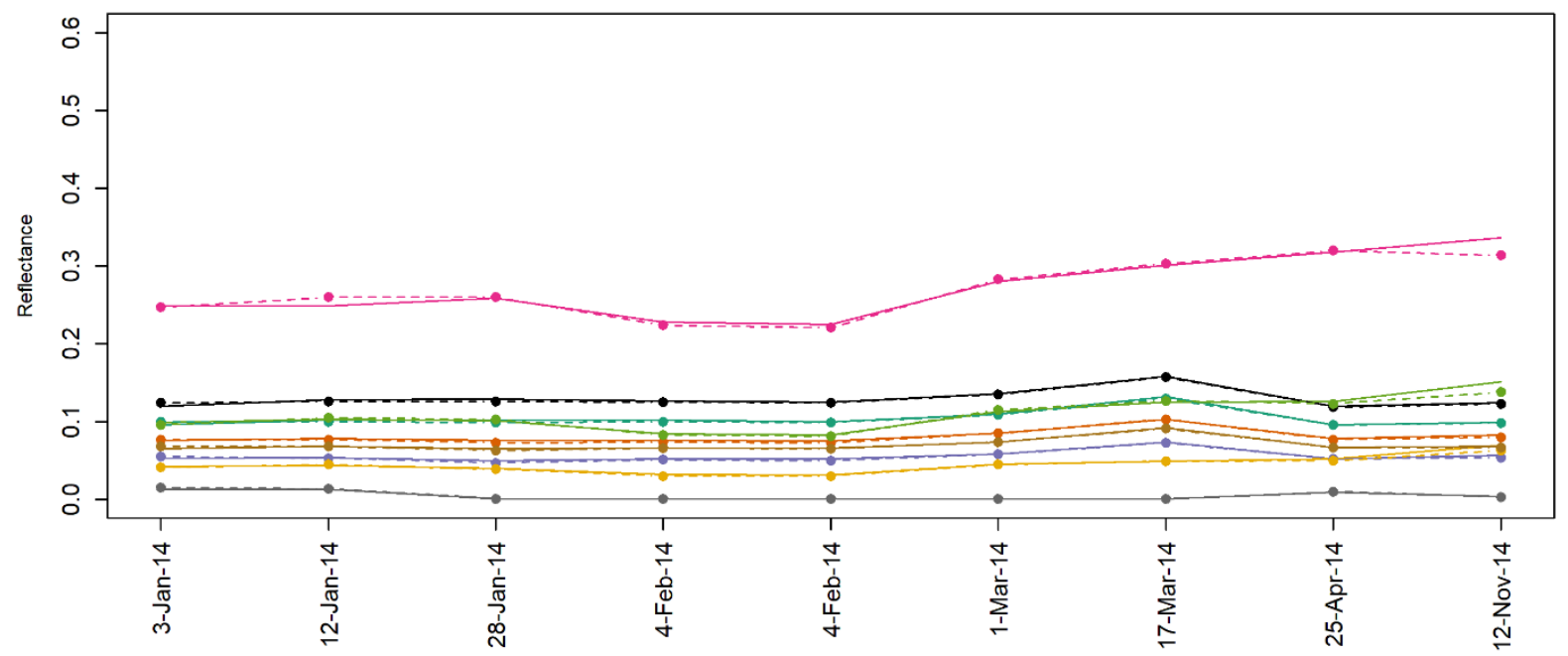


Figure 4: The Spectral difference between the plane and the reference sites from Landsat 8. A: Heathrow Airplane, B: Airplane Home in the US, C: Cambodian Jungle. Solid line: airplane shapefile, dashed: reference. Black: B1, green: B2, tenne: B3, blue: B4, cerise: B5, christi: B6, gamboge: B7, hot toddy: B8, gray: B9.

\subsection{The Panchromatic difference}

In both the Heathrow Airport and Airplane Home case, in the panchromatic band (band 8 ), the reflectance of plane site higher than the reflectance of references. The reflectance of the planes was $0.25 \pm 0.13$ and $0.09 \pm 0.02$ for Heathrow and Airplane Home, respectively (Figure 5). While the reflectance of the reference sites in the first case was $0.09 \pm 0.02$ and in the second case was $0.05 \pm 0.01$. It suggests that panchromatic band of Landsat 8 capable to distinguish between the plane site and the vegetated reference location. In contrast, in the case of Cambodian Jungle, the reflectance of the plane shapefile was $0.11 \pm 0.13$ and reflectance of the reference site was $0.11 \pm 0.14$. It means there is no difference between them as well as there is no plane in the claimed crashed site and both areas are dominated by the tree.

A

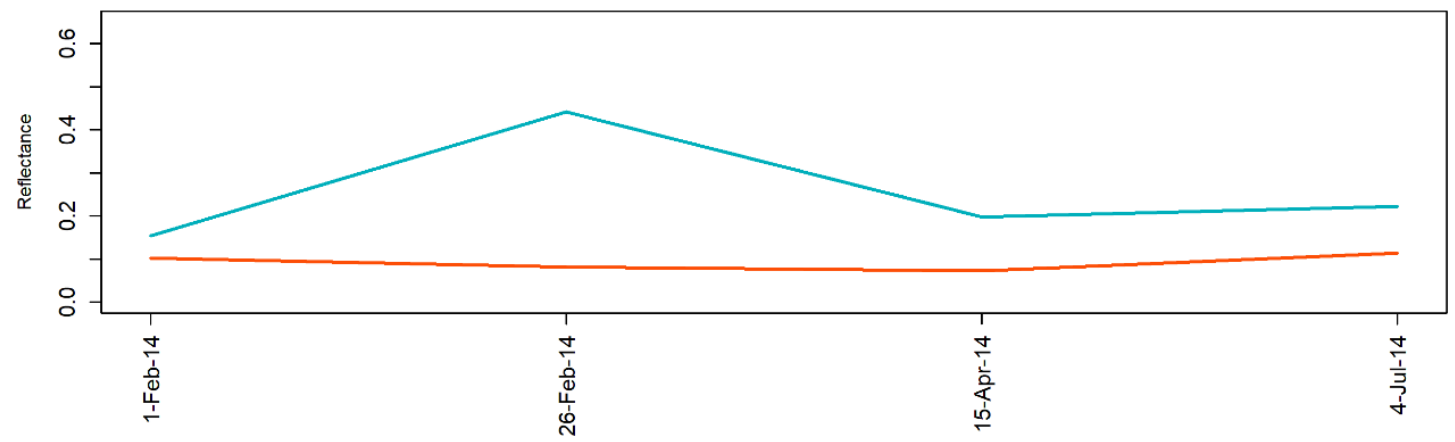

B

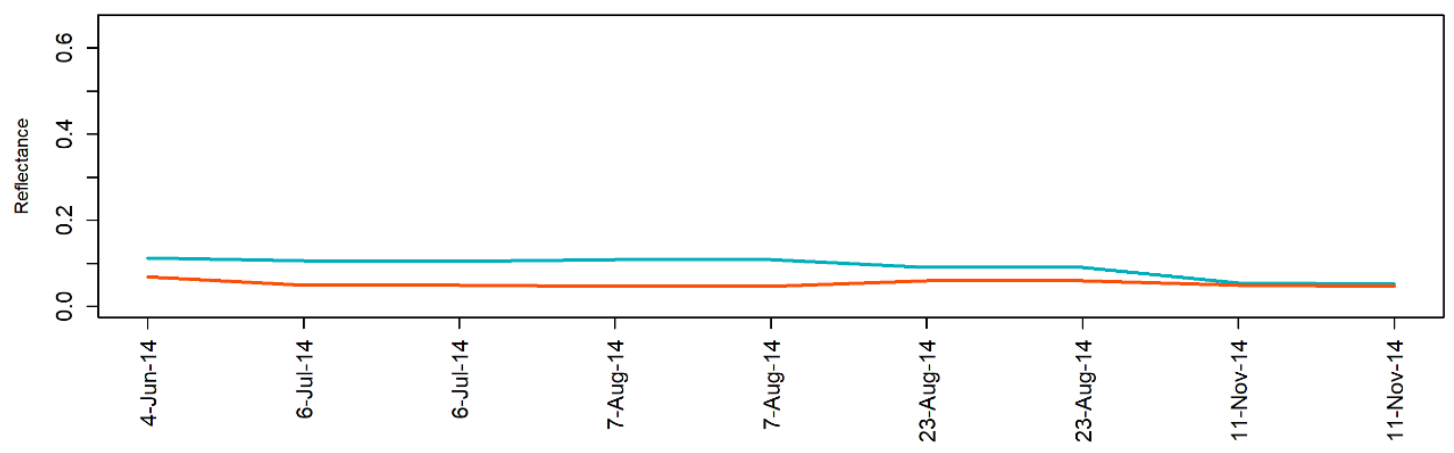

C

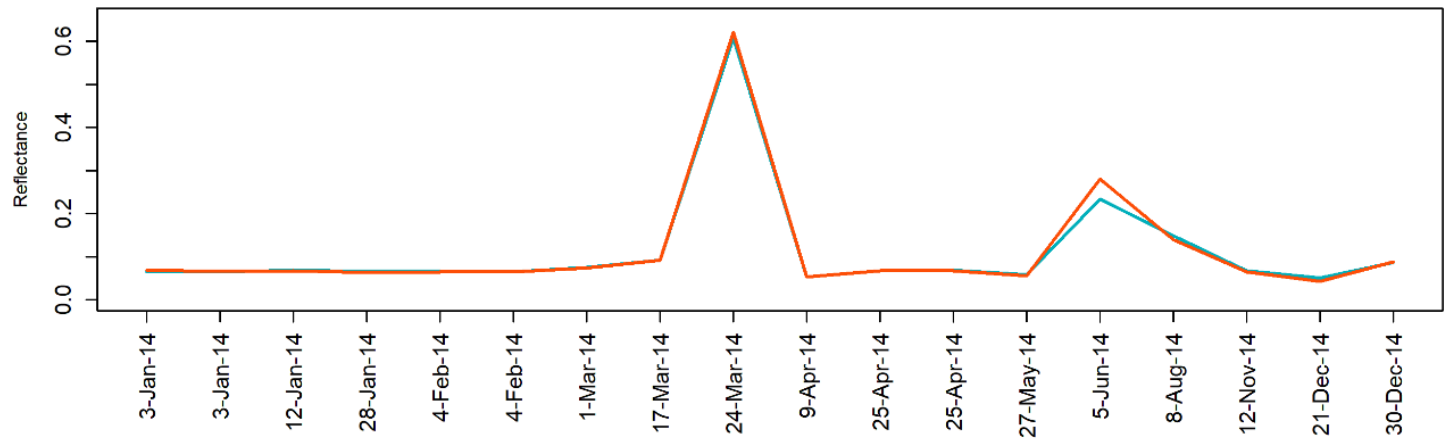


Figure 5: The Panchromatic difference between the plane and the reference sites from Landsat 8. A: Heathrow Airplane, B: Airplane Home in the US, C: Cambodian Jungle. Blue is airplane shapefile and orange is a reference site.

\subsection{Thermal band difference}

In the study site of Heathrow Airport, there is a seasonal fluctuation between top-ofatmosphere (TOA) LST of the aircraft and the reference sites. However, in Airplane Home case, average TOA LST of shapefile in both b10 from 2014 to 2017 was higher than average TOA LST of the vegetated reference site (Figure 6). LST of the plane was 292.31 $\pm 9.47 \mathrm{~K}$ whereas LST of the reference was $290.91 \pm 7.99 \mathrm{~K}$. It means LST of the plane was $1.41 \mathrm{~K}$ higher.

Regarding the Cambodian Jungle sample, generally, there is no difference between LST of the aircraft site $(294.58 \pm 2.95 \mathrm{~K})$ and LST of the reference $(294.54 \pm 2.99 \mathrm{~K})$. For instance, on $25^{\text {th }}$ April of 2014, after missing MH370, LST of the claimed aircraft site was $294.28 \mathrm{~K}$ and LST of the reference site was $294.33 \mathrm{~K}$. It means no difference observed between locations in the thermal band, therefore, it suggests there is no aircraft in the location.
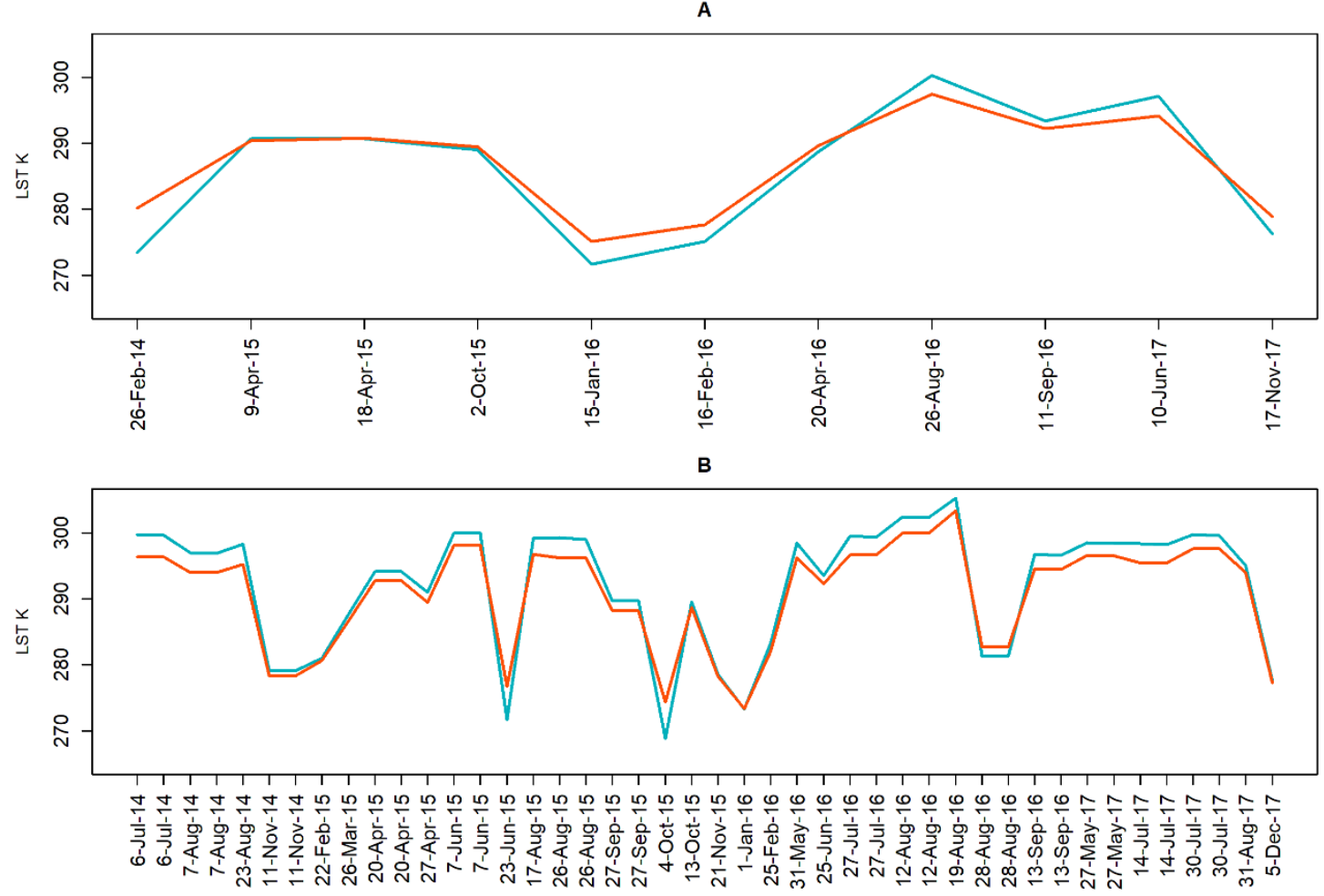

C

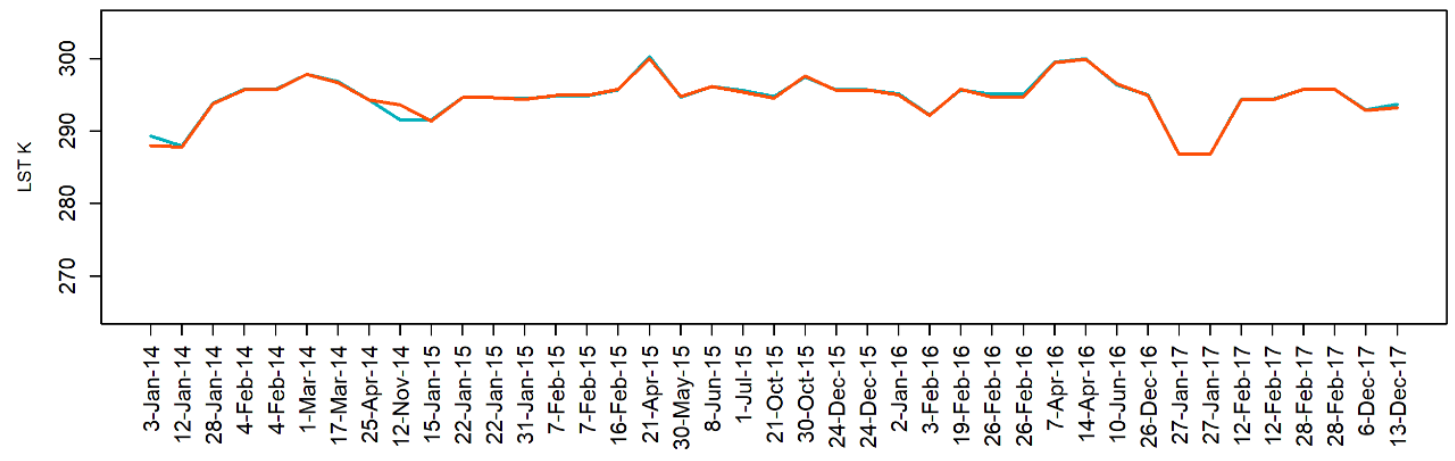


Figure 6: The Thermal difference between the plane and the reference sites from Landsat 8. A: Heathrow Airplane, B: Airplane Home in the US, C: Cambodian Jungle. Blue is airplane shapefile and orange is a reference site.

\section{Discussion}

Crashing as well as disappearing aircraft, usually, cause human and finance damage. In case of crash down the plane in the remote and bumpy area such as jungle, like what occurs with MH370, remain a mystery for a long time. Disclose these mysteries require great effort and costly research. At that time, perhaps several individuals claim they discovered it in different locations only based on visual view on satellite image like Google Earth software. Whereas using remote sensing techniques such as different indices, composition, and bands is the necessary and scientific approach.

Landsat 8 images even it has less resolution compared with commercial high-resolution satellite images, however, its advantage is having several bands and the possibility of using it for various scientific purposes as well as Landsat data freely available for the long period. Landsat 8 pixels have 15, 30 and $100 \mathrm{~m}$ resolution for panchromatic, visible and thermal bands, respectively. Even if the plane body does not cover all size of the pixel, due to the digital number of the pixels considered as the average of the entire area of the pixel, having the plane body even in part of the pixel is capable to change the value of the pixels compared to its surrounding pixels.

One benefit of this research is the possibility of distinguishing between the fly plane during the satellite image acquired and the plane actually on the ground. Especially, this research assists in investigate of the plane in a jungle. Moreover, these results subseries the relative of victims of the airplane crash, airline company and component authorities for the missed airplane.

\section{Conclusion}

Remote sensing data besides techniques used for various purposes including natural disasters such as earthquake and flood. The research aims to consume freely available Landsat 8 images for investigating crashed airplanes such as MH370. Due to the materials and color of aircraft body different from the site of a crashed aircraft, moreover, it should be the characteristics of the aircraft shapefile different in terms of albedo, temperature and vegetation index degree.

The result of this research realized that in albedo, panchromatic, average of the thermal band, bands 1 to 5, plane sites have a higher value compared to the value of green background area. In contrast, the reference samples have higher NDVI compared to NDVI of plane sites. The research observed Landsat 8 data as well as methods used in this research, especially, NDVI, albedo and band 4, able to distinguish between the plane and its surrounding green area.

Regarding the case of Cambodian Jungle, in albedo, NDVI, spectral difference, panchromatic and thermal band, in other words, in all used methods in this study, there was no significant difference between the claimed crash site $\left(12^{\circ} 05^{\prime} 20^{\prime \prime} \mathrm{N} 104^{\circ} 09^{\prime} 06^{\prime \prime} \mathrm{E}\right)$ and the sample of reference. Therefore, our result suggests that during the research period, there was no plane on the location, in addition, MH370 not crashed in this site.

Even remote sensing may have the ability to differentiate between various land cover background and airplane, this research only limited to green background area such as a forest. The result of the study suggests there is no an airplane on the claimed crashed site, not entire Cambodian Jungle which is a wide as well as a dense jungle. To confirm as well as complement the ability of remote sensing data and techniques to investigate disappeared airplane, we suggest 
performing further research besides using different remote sensing data in different study site within the various land cover.

\section{Reference}

1. Karen E. Joyce, Stella E. Belliss, Sergey V. Samsonov, Stephen J. McNeill, Phil J. Glassey, S. E. B. A review of the status of satellite remote sensing and image processing techniques for mapping natural hazards and disasters. (2009). Available at: https://journals.sagepub.com/doi/abs/10.1177/0309133309339563. (Accessed: 13th November 2018)

2. Stefanov, W. L. \& Evans, C. A. Data Collection for Disaster Response from the International Space Station. ISPRS - Int. Arch. Photogramm. Remote Sens. Spat. Inf. Sci. XL-7/W3, 851855 (2015).

3. Rosen, P. A. et al. Synthetic aperture radar interferometry. Proc. IEEE 88, 333-382 (2000).

4. Kwoun, O.-I., Lu, Z., Neal, C. \& Wicks, C. Quiescent deformation of the Aniakchak Caldera, Alaska, mapped by InSAR. Geology 34, 5-8 (2006).

5. Torres, R. et al. Monitoring the evolution of the Pasig-Potrero alluvial fan, Pinatubo Volcano, using a decade of remote sensing data. J. Volcanol. Geotherm. Res. 138, 371-392 (2004).

6. Tansey, K. et al. A new, global, multi-annual (2000-2007) burnt area product at $1 \mathrm{~km}$ resolution. Geophys. Res. Lett. 35, (2008).

7. Mojaddadi, H., Pradhan, B., Nampak, H., Ahmad, N. \& Ghazali, A. H. bin. Ensemble machine-learning-based geospatial approach for flood risk assessment using multi-sensor remote-sensing data and GIS. Geomat. Nat. Hazards Risk 8, 1080-1102 (2017).

8. Jansen, E., Coppini, G. \& Pinardi, N. Drift simulation of MH370 debris using superensemble techniques. Nat. Hazards Earth Syst. Sci. 16, 1623-1628 (2016). 
9. Nesterov, O. Consideration of various aspects in a drift study of MH370 debris. Ocean Sci. 14, 387-402 (2018).

10. Okolia, E. J., Enegbumab, W. I. \& Bahru, U. J. OVERVIEW OF REMOTE SENSING APPLICATION FOR SEARCH OF MH370. J. Teknol. 77, 63-68 (2015).

11. AlBattat, D. A. Biometric Technologies and Airline Security: A Case Study of Flight MH370.

12. García Garrido, V., Mancho, A. M., Wiggins, S. \& Mendoza Parra, C. A. A dynamical systems perspective on the absence of debris associated with the disappearance of flight MH370. Nonlinear Process. Geophys. Discuss. 22, 701-712 (2015).

13. $\mathrm{Xu}, \mathrm{Y}$. et al. Rapid Airplane Detection in Remote Sensing Images Based on Multilayer Feature Fusion in Fully Convolutional Neural Networks. Sensors 18, 2335 (2018).

14. Hemalatha, P. C. \& ME, M. M. A. Aircraft Recognition in High Resolution Satellite Images. Int. J. Eng. Sci. IJES 3, 21-25 (2014).

15. Aytekin, Ö., Zöngür, U. \& Halici, U. Texture-based airport runway detection. IEEE Geosci. Remote Sens. Lett. 10, 471-475 (2013).

16. Yao, X., Han, J., Guo, L., Bu, S. \& Liu, Z. A coarse-to-fine model for airport detection from remote sensing images using target-oriented visual saliency and CRF. Neurocomputing 164, 162-172 (2015).

17. Liu, L. \& Shi, Z. Airplane detection based on rotation invariant and sparse coding in remote sensing images. Opt.-Int. J. Light Electron Opt. 125, 5327-5333 (2014).

18. Zhang, W., Sun, X., Wang, H. \& Fu, K. A generic discriminative part-based model for geospatial object detection in optical remote sensing images. ISPRS J. Photogramm. Remote Sens. 99, 30-44 (2015). 
19. Cheng, G. \& Han, J. A survey on object detection in optical remote sensing images.

ISPRS J. Photogramm. Remote Sens. 117, 11-28 (2016).

20. Rasul, A. et al. Applying Built-Up and Bare-Soil Indices from Landsat 8 to Cities in Dry Climates. Land 7, 81 (2018).

21. Roy, D. P. et al. Landsat-8: Science and product vision for terrestrial global change research. Remote Sens. Environ. 145, 154-172 (2014).

22. Jia, K. et al. Land cover classification using Landsat 8 Operational Land Imager data in Beijing, China. Geocarto Int. 29, 941-951 (2014).

23. Fahnestock, M. et al. Rapid large-area mapping of ice flow using Landsat 8. Remote Sens. Environ. 185, 84-94 (2016).

24. Rasul, A., Balzter, H. \& Smith, C. Applying a normalized ratio scale technique to assess influences of urban expansion on land surface temperature of the semi-arid city of Erbil. Int. J. Remote Sens. 38, 3960-3980 (2017).

25. Webb, C. O. Vegetation mapping in Phnom Samkos and Phnom Aural Wildlife Sanctuaries, Cardamom Mountains, Cambodia. Unpubl. Rep. Fauna Flora Int. Phnom Penh (2005).

26. Council for the Development of Cambodia. Cambodia Municipality and Province Investment Information. (2013).

27. Office, M. London Heathrow Airport climate. Available at: https://www.metoffice.gov.uk/public/weather/climate/gcpsvf37b. (Accessed: 16th November 2018)

28. About Hillsboro. Hillsboro Chamber of Commerce 
29. Google Earth Engine. Available at: https://earthengine.google.com. (Accessed: 19th November 2018)

30. Coakley, J. A. REFLECTANCE AND ALBEDO, SURFACE. in Encyclopedia of Atmospheric Sciences 1914-1923 (Elsevier, 2003). doi:10.1016/B0-12-227090-8/00069-5

31. Santamouris, M. Heat Island Research in Europe: The State of the Art. Advances in Building Energy Research (2013). doi:10.4324/9781849770378-12

32. Barry, R. \& Chorley, R. Atmosphere, Weather and Climate. (Routledge, 2002).

33. Waters, R., Allen, R., Bastiaanssen, W., Tasumi, M. \& Trezza, R. Surface energy balance algorithms for land, Idaho implementation, advanced training and users manual. NASA USA (2002).

34. Karnieli, A. et al. Use of NDVI and Land Surface Temperature for Drought Assessment: Merits and Limitations. J. Clim. 23, 618-633 (2010).

35. Remote Sensing Phenology NDVI the Foundation. Available at: https://phenology.cr.usgs.gov/ndvi_foundation.php. (Accessed: 16th November 2018)

36. Kokaly, R. F. et al. USGS Spectral Library Version 7. 68 (U.S. Geological Survey, 2017).

37. Li, Z. et al. Landsat 15-m Panchromatic-Assisted Downscaling (LPAD) of the 30-m Reflective Wavelength Bands to Sentinel-2 20-m Resolution. Remote Sens. 9, 755 (2017).

\section{Acknowledgments}

The author would like to thank the Google Earth Engine program. Furthermore, much gratitude goes to the USGS, for providing the research with liberates Landsat 8 images.

\section{Author Contributions}

Data curation, A.R.; Formal analysis, A.R.; Investigation, A.R.; Methodology, A.R.; Resources, A.R.; Validation, A.R.; Visualization, A.R.; Writing — original draft, A.R.; Writing-review \& 
editing, A.R..

\section{Appendixes}

Appendix 1: Characteristics of Landsat 8.

\begin{tabular}{lllc}
\hline Bands & Bands Name & $\begin{array}{l}\text { Wavelength } \\
\text { (micrometers) }\end{array}$ & $\begin{array}{c}\text { Resolution } \\
\text { (meters) }\end{array}$ \\
\hline $\mathbf{1}$ & Coastal/Aerosol (CA) & $0.435-0.451$ & 30 \\
\hline $\mathbf{2}$ & Blue & $0.452-0.512$ & 30 \\
\hline $\mathbf{3}$ & Green & $0.533-0.590$ & 30 \\
\hline $\mathbf{4}$ & RED & $0.636-0.673$ & 30 \\
\hline $\mathbf{5}$ & NIR & $0.851-0.879$ & 30 \\
\hline $\mathbf{6}$ & SWIR1 & $1.566-1.651$ & 30 \\
\hline $\mathbf{7}$ & SWIR2 & $2.107-2.294$ & 30 \\
\hline $\mathbf{8}$ & Panchromatic & $0.503-0.676$ & 15 \\
\hline
\end{tabular}



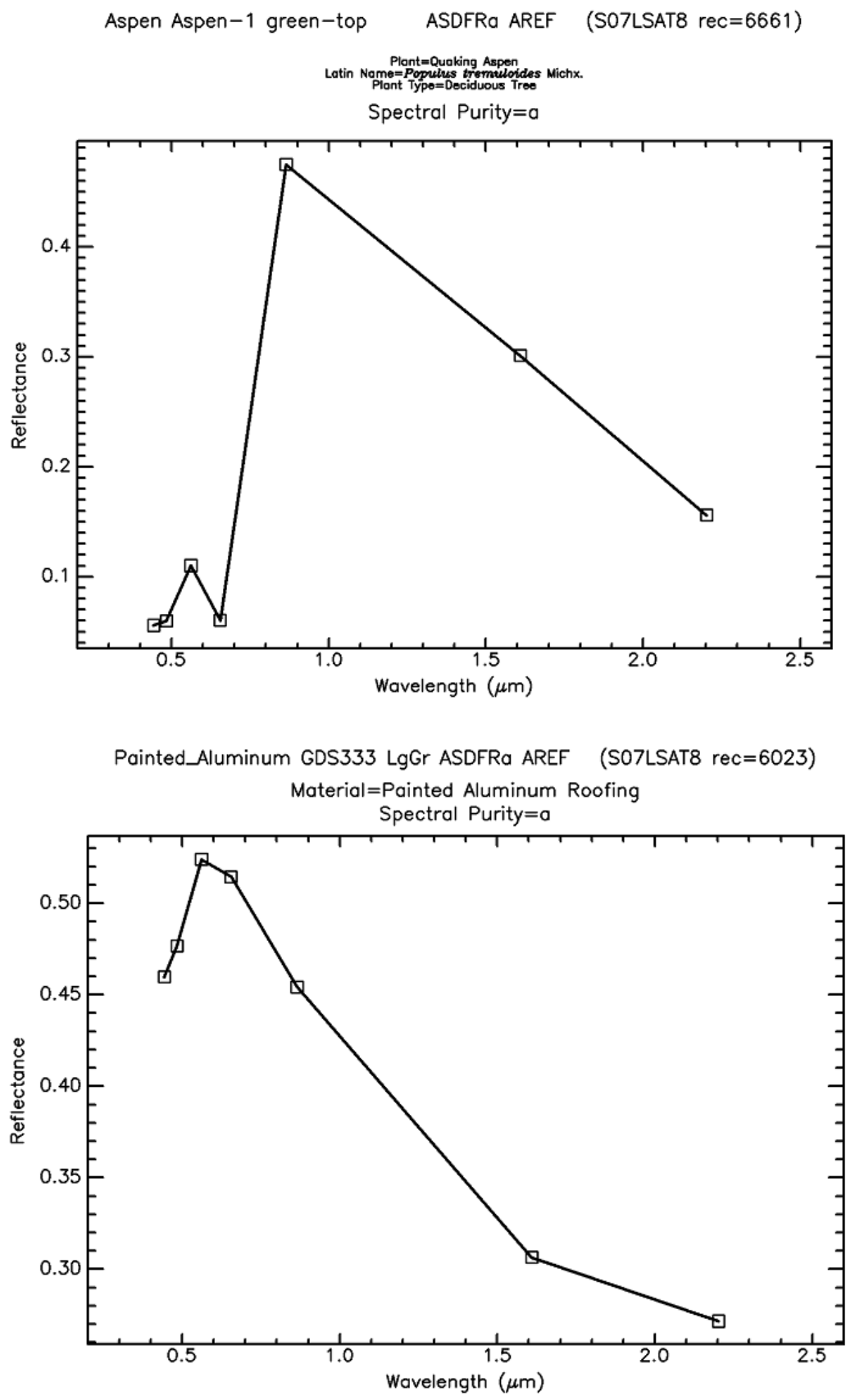

Appendix 2: the Spectral difference between painted aluminum and aspen tree in Landsat 8 from USGS Spectral Library Version $7^{36}$. 